\title{
Reduction in the Interfacial Trap Density of Mechanochemically Synthesized $\mathrm{MAPbI}_{3}$
}

\author{
Daniel Prochowicz, ${ }^{*, t, a, b}$ Pankaj Yadav ${ }^{\dagger, a}$ Michael Saliba, ${ }^{a}$ Marcin Saski,${ }^{b}$ Shaik M. Zakeeruddin, ${ }^{a}$ \\ Janusz Lewiński ${ }^{*, b, c}$ and Michael Grätzel ${ }^{*, a}$
}

${ }^{\text {a }}$ Laboratory of Photonics and Interfaces, Institute of Chemical Sciences and Engineering, School of Basic Sciences, Ecole Polytechnique Fédérale de Lausanne (EPFL), CH-1015 Lausanne, Switzerland.

${ }^{\mathrm{b}}$ Institute of Physical Chemistry, Polish Academy of Sciences, Kasprzaka 44/52, 01-224 Warsaw, Poland.

${ }^{\mathrm{c}}$ Faculty of Chemistry, Warsaw University of Technology, Noakowskiego 3, 00-664 Warsaw, Poland.

Keywords: photovoltaic, perovskite solar cells, mechanoperovskite, $\mathrm{MAPb}_{3}$, hysteresis, trap density.

\begin{abstract}
Organo-lead halide perovskites have emerged as a promising light harvesting materials for solar cells. The ability to prepare high quality films with a low concentration of defects is essential for obtaining high device performance. Here, we advance the procedure for the fabrication of efficient perovskite solar cells (PSCs) based on mechanochemically synthesized $\mathrm{MAPbI}_{3}$. The use of mechano-perovskite for the thin film formation provides a high degree of control of the stoichiometry and allows for the growth of relatively large crystalline grains. The best device achieved a maximum PCE of $17.5 \%$ from a current-voltage scan $(J-V)$, which stabilized at $16.8 \%$ after $60 \mathrm{sec}$ of maximum power point tracking. Strikingly, PSCs based on $\mathrm{MAPbI}_{3}$ mechanoperovskite exhibit lower "hysteretic" behaviour in comparison to that comprising $\mathrm{MAPbI}_{3}$ obtained from the conventional solvothermal reaction between
\end{abstract}


$\mathrm{PbI}_{2}$ and MAI. To gain a better understanding of the difference in $J-V$ hysteresis we analyze the charge/ion accumulation mechanism and identify the defect energy distribution in the resulting $\mathrm{MAPbI}_{3}$ based devices. These results indicate that the use of mechanochemically synthesized perovskites provides a promising strategy for the formation of crystalline film demonstrating slow charge recombination and low trap density.

\section{INTRODUCTION}

In the past few years, hybrid organic-inorganic lead halide perovskites have emerged as one of the most promising materials for next generation solar cells owing to their simple solution-processed technique and high efficiency. ${ }^{1,2}$ Since perovskite solar cells (PSCs) were first introduced by the Miyasaka group in $2009,{ }^{3}$ the power conversion efficiency (PCE) has been improved from $3.8 \%$ to more than $22 \%$ in $2017 ., 4,6$ To develop high-performance PSCs, one challenge is morphology and quality control of the perovskite thin films. ${ }^{7,89}$ Full film coverage on the substrate surface reduces shunting paths and improves light absorption, ${ }^{10}$ while a low concentration of defects mitigates the photocurrentvoltage $(J-V)$ hysteresis by suppressing the charge trapping. ${ }^{11,12}$ Moreover, the crystal structure and intrinsic electronic properties of $\mathrm{MAPbI}_{3}$ have been proposed to possibly influence on the photovoltaic parameters. ${ }^{13}$ Very recently, the exsistance of crystallographic twin domains in thin film has been also suggested to play a role in the photovoltaic properties of $\mathrm{MAPbI}_{3}{ }^{14}$

Most of the reported perovskite solar cells are based on methylammonium lead triiodide $\left(\mathrm{MAPbI}_{3}\right)$ due to a long electron/hole diffusion length, high absorption coefficient, and excellent defect tolerance. ${ }^{15,16}$ One commonly used method to prepare $\mathrm{MAPbI}_{3}$ thin films is the facile one-step spincoating using a precursor composed from MAI and $\mathrm{PbI}_{2}$ mixture in a organic solvent (see Scheme 1, path 1). ${ }^{17,18}$ However, it is challenging to obtain highly crystalline perovskite films with full surface coverage using this procedure. ${ }^{19}$ Thus, several modifications including solvent engineering, ${ }^{20}$ fast deposition-crystallization $^{21}$ and the addition of different additives ${ }^{22-26}$ have been developed. These 
complex preparation methods are sensitive to small changes in the precursors composition and thus reproducibility remains an issue for improving $\mathrm{MAPbI}_{3}$ films ${ }^{24}$ towards the highest performing multication perovskites. ${ }^{5}$

Another (less often explored) way to fabricate thin film through one-step deposition method is to use powdered crystalline $\mathrm{MAPbI}_{3}$ perovskite as precursor (see Scheme 1, path 2). ${ }^{27,28}$ Using this approach, Wang et al. reported on large grained $\mathrm{MAPbI}_{3}$ films starting from powdered single-crystals. ${ }^{27}$ Importantly, the corresponding devices exhibited a higher degree of reproducibility, albeit at a low efficiency $11.7 \%$. Recently, we utilized mechanochemically synthesized polycrystalline $\mathrm{MAPbI}_{3}$ powder as precursor to fabricate solar cell devices via a one-step deposition method in DMF to enable perovskite thin films with higher phase purity and superior photovoltaic performance (with a PCE of $9.1 \%$ ) as compared to conventional solution processed devices. ${ }^{28}$ These works demonstrated that the use of perovskite powders for thin film formation has advantages in providing a higher degree of control of the stoichiometry, high reproducibility, stability and material phase purity. Moreover, $J-V$ hysteresis in the fabricated $\mathrm{MAPbI}_{3}$ devices was reduced compared to solution-processed solid-state photovoltaic devices which was attributed to the presence of the lower number of defects in particular electron or hole traps. However, the physical origin of such behavior has not been thoroughly investigated.

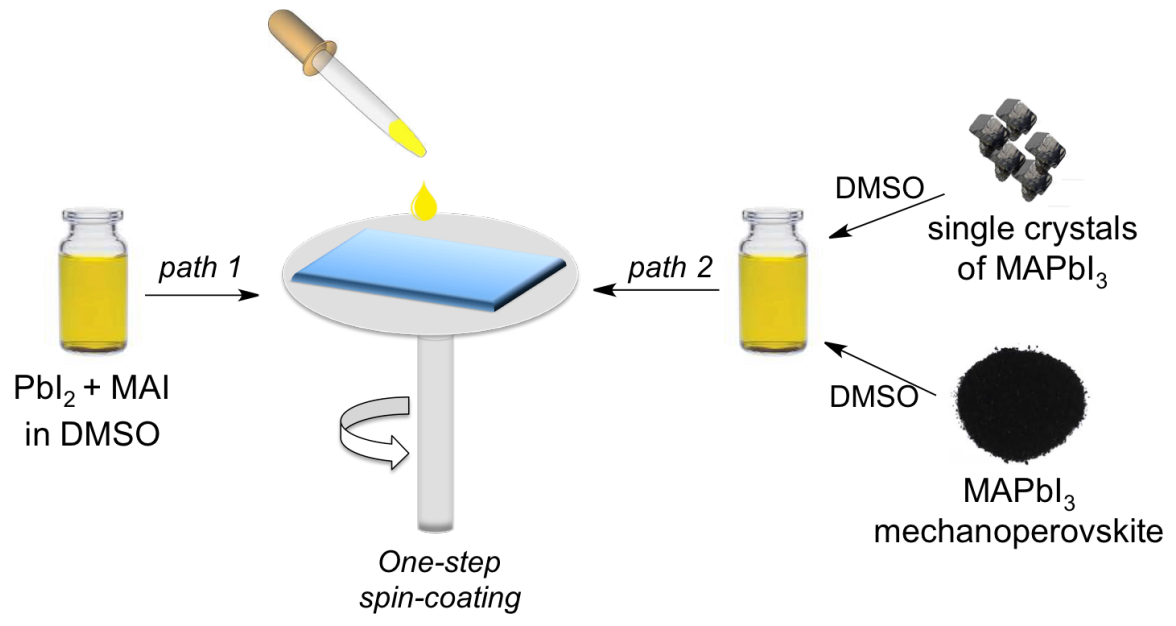

Scheme 1. Schematic procedure for the one-step spin-coating deposition method of precursors composed from MAI and $\mathrm{PbI}_{2}$ mixture (path 1) and powdered crystalline perovskites (path 2). 
Herein we report on development of a procedure to fabricate efficient PSCs based on mechanochemically synthesized $\mathrm{MAPbI}_{3}$ by using antisolvent deposition method, which provides devices with a maximum PCE of $17.5 \%$ and open circuit voltage of $1.09 \mathrm{~V}$. Moreover, PSCs based on $\mathrm{MAPbI}_{3}$ mechanoperovskite exhibit lower "hysteretic" behaviour during current density-voltage measurements compared to devices comprising $\mathrm{MAPbI}_{3}$ perovskites obtained from the conventional solvothermal reaction between $\mathrm{PbI}_{2}$ and MAI. To gain a better understanding of the difference in $J-V$ hysteresis and to characterize and identify the defect energy level distribution in the resulting $\mathrm{MAPbI}_{3}$ based devices we used admittance spectroscopy and Mott-Schottky analysis. The use of mechanochemically synthesized $\mathrm{MAPbI}_{3}$ provides a crystalline film demonstrating slow charge recombination and low trap density. Moreover, our detailed spectroscopical investigations shed light on the fundamental mechanisms underlying the interfacial phenomenon leading to hysteresis.

\section{RESULTS AND DISCUSSION}

Initially, we prepared the stock solution of $\mathrm{MAPbI}_{3}$ mechanoperovskite (referred to as $\mathrm{MAPbI}_{3}(\mathrm{~m})$ ) and a mixture composed of equimolar amounts of MAI and $\mathrm{PbI}_{2}$ (hereinafter referred to as $\mathrm{MAPbI}_{3}(\mathrm{~s})$ ) in an organic solvent. Thereafter these solutions were used to prepare thin films via the fast crystallization deposition method ${ }^{21}$ (for more details of perovskite films formation see Experimental Section). To evaluate the quality of thin films we characterized their morphological properties. Finally, we fabricated solar cell devices from $\mathrm{MAPbI}_{3}(\mathrm{~m})$ and $\mathrm{MAPbI}_{3}(\mathrm{~s})$ precursors using a stack of glass/fluorine-doped tin oxide/compact $\mathrm{TiO}_{2} /$ mesoporous $\mathrm{TiO}_{2} /$ perovskite/spiro-OMeTAD/gold architecture and compared their photovoltaic as well as spectroscopic properties.

Synthesis and film characterization. $\mathrm{MAPbI}_{3}(\mathrm{~m})$ was prepared by neat grinding of MAI and $\mathrm{PbI}_{2}$ according to the previously reported procedure. ${ }^{28}$ The stock solution of $\mathrm{MAPbI}_{3}(\mathrm{~m})$ particles was prepared by dissolving them in dimethyl sulfoxide (DMSO) by vigorous stirring at $60^{\circ} \mathrm{C}$. 
Similarly, a perovskite stock solution of $\mathrm{MAPbI}_{3}(\mathrm{~s})$ was prepared by dissolving equimolar amounts of $\mathrm{PbI}_{2}$ and $\mathrm{MAI}$ in DMSO at $60^{\circ} \mathrm{C}$. These processes resulted in the formation of yellow solutions suggesting the formation of $\mathrm{PbI}_{2}-\mathrm{DMSO}$ adducts. ${ }^{29}$ The X-ray diffraction (XRD) patterns of the resulting $\mathrm{MAPbI}_{3}$ films are compared in Figure $\mathrm{S} 1$. Both the perovskite $\mathrm{MAPbI}_{3}$ films show strong diffraction peaks for (110), (220) and (310) at $2 \theta$ of $14.1^{\circ}, 28.4^{\circ}$ and $31.8^{\circ}$, indicating the typical tetragonal phase of perovskite. ${ }^{30}$ Furthermore, there are no detectable MAI or $\mathrm{PbI}_{2}$ phase peaks, confirming that the samples are also compositionally pure. Scanning electron microscopy (SEM) was used to investigate the grain size and the surface morphology, which are known to influence the device performance. ${ }^{31,32,33}$ The top-view SEM image of $\mathrm{MAPbI}_{3}(\mathrm{~m})$ and $\mathrm{MAPbI}_{3}(\mathrm{~s})$ are shown in Figure 1. These SEM images clearly show the compact and pin-hole free surface coverage with large grains in the range of $100-350 \mathrm{~nm}$. The average grain size of perovskites in $\mathrm{MAPbI}_{3}(\mathrm{~m})$ and $\mathrm{MAPbI}_{3}(\mathrm{~s})$ based films is estimated to be $\sim 200 \mathrm{~nm}$ and $180 \mathrm{~nm}$, respectively (for corresponding crystal-size distributions histograms see Figure S2).

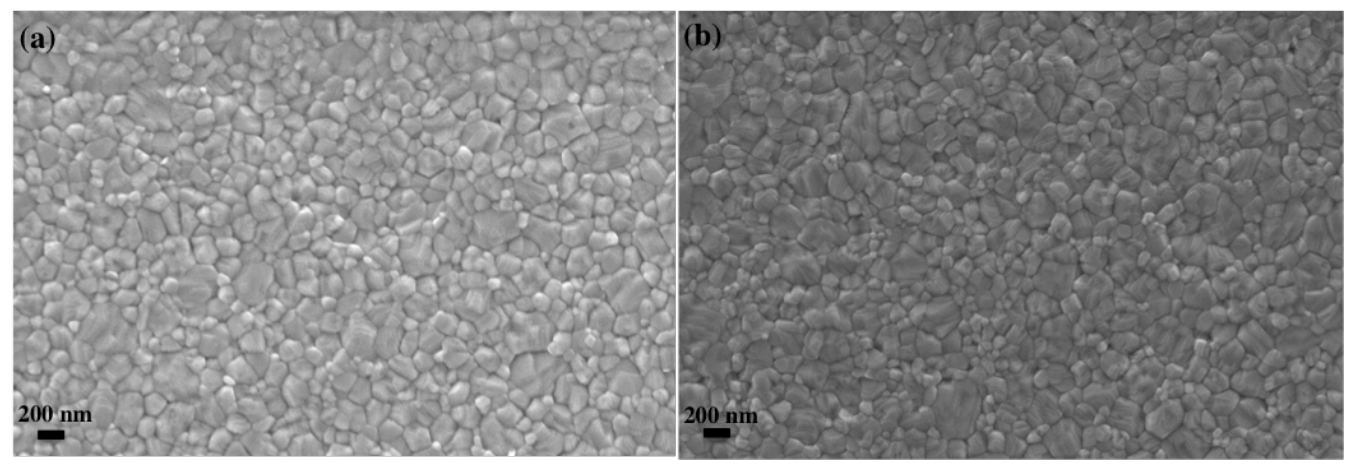

Figure 1. Top view SEM image of perovskite films (a) $\mathrm{MAPbI}_{3}(\mathrm{~m})$ and (b) $\mathrm{MAPbI}_{3}(\mathrm{~s})$ on FTO/compact $\mathrm{TiO}_{2} /$ mesoporous $\mathrm{TiO}_{2}$.

Device characterization. The mesoporous $\mathrm{TiO}_{2}$-based $\mathrm{PSC}$ was selected as the device structure. The cross-sectional SEM images of PSCs prepared with an $\mathrm{MAPbI}_{3}(\mathrm{~m})$ and $\mathrm{MAPbI}_{3}(\mathrm{~s})$ 
based films showed a well-defined structure with clear and flat interfaces (Figure S3). In both devices, the thickness of the perovskite layers was measured at $\sim 200 \mathrm{~nm}$. The current densityvoltage $(J-V)$ characteristics of standard mesoporous PSCs with $\mathrm{MAPbI}_{3}(\mathrm{~m})$ and $\mathrm{MAPbI}_{3}(\mathrm{~s})$ under 1 Sun illumination (AM 1.5G) in forward and backward direction is shown in Figure 2a. The best performing $\mathrm{MAPbI}_{3}(\mathrm{~m})$ and $\mathrm{MAPbI}_{3}(\mathrm{~s})$ based device demonstrates a PCE of $17.58 \%$ and $17.91 \%$, respectively (for the statistic histogram of photovoltaic parameters from the collected devices see Figure $\mathrm{S} 5$ and see Figure $\mathrm{S} 6$ for dark $J-V$ characteristics of $\mathrm{MAPbI}_{3}(\mathrm{~m})$ and $\mathrm{MAPbI}_{3}(\mathrm{~s})$ devices). The performance of $\mathrm{MAPbI}_{3}(\mathrm{~m})$ based device is limited by the lower photocurrent. The $\mathrm{MAPbI}_{3}(\mathrm{~m})$ based device exhibits a open circuit voltage $\left(\mathrm{V}_{\mathrm{OC}}\right)$ of $1.06 \mathrm{~V}$, short-circuit current $\left(\mathrm{J}_{\mathrm{SC}}\right)$ of $20.91 \mathrm{~mA} / \mathrm{cm}^{2}$, fill factor $(\mathrm{FF})$ of $65 \%$ and power conversion efficiency (PCE) of $14.53 \%$ in the forward scan, whereas one observes a $\mathrm{V}_{\mathrm{OC}}$ of $1.09 \mathrm{~V}, \mathrm{~J}_{\mathrm{SC}}$ of $20.94 \mathrm{~mA} / \mathrm{cm}^{2}, \mathrm{FF}$ of $77 \%$ and PCE of $17.58 \%$ in the reverse scan. On the other hand, $\mathrm{MAPbI}_{3}(\mathrm{~s})$ based device exhibits a $\mathrm{V}_{\mathrm{OC}}$ of $1.06 \mathrm{~V}, \mathrm{~J}_{\mathrm{SC}}$ of $21.32 \mathrm{~mA} / \mathrm{cm}^{2}$, FF of $62 \%$ and PCE of $14.09 \%$ in the forward scan, and a $\mathrm{V}_{\mathrm{OC}}$ of $1.07 \mathrm{~V}, \mathrm{~J}_{\mathrm{SC}}$ of $21.35 \mathrm{~mA} / \mathrm{cm}^{2}$, FF of $78 \%$ and PCE of $17.91 \%$ in the backward scan. Thus, the devices with $\mathrm{MAPbI}_{3}(\mathrm{~m})$ perovskite particles and $\mathrm{MAPbI}_{3}(\mathrm{~s})$ exhibit very similar performance in contrast to our pioneering report in which $\mathrm{MAPbI}_{3}(\mathrm{~m})$ gave superior device performance. ${ }^{28}$ Moreover, the photovoltaic parameters in forward scan are the most affected in these two devices, while there is an insignificant difference observed in backward scan (Figure 2a). However, $\mathrm{MAPbI}_{3}(\mathrm{~m})$ PSCs exhibit lower hysteresis and higher $\mathrm{V}_{\mathrm{OC}}$ compared to $\mathrm{MAPbI}_{3}(\mathrm{~s})$ devices. We found that the hysteresis characteristics affect the $\mathrm{FF}$ (forward scan) in these two devices, but this effect is more pronounced in $\mathrm{MAPbI}_{3}(\mathrm{~s})$ mainly at the maximum power point leading to a higher hysteresis (for statistics of $\triangle \mathrm{PCE}$ see Figure S7) ${ }^{34}$ In addition, we report the PCE evolution of the devices during a continuous operation at the 
maximum power point (MPP) tracking for $60 \mathrm{sec}$ under 1 sun conditions (Figure S8). The devices made with $\mathrm{MAPbI}_{3}(\mathrm{~s})$ and $\mathrm{MAPbI}_{3}(\mathrm{~m})$ show the stabilized PCE of $17.1 \%$ and $16.8 \%$, respectively.

In principle, considering an efficient charge transport into the perovskite absorber layer and the kinetics at interface $\left(\mathrm{TiO}_{2}\right.$ /perovskite) that facilitates charge accumulation, the net difference in $J-V$ characteristics through scanning in the forward and backward direction is analogous to the surface property of perovskite. ${ }^{35,36}$ According to recent reports, the charge/ion accumulation at $\mathrm{TiO}_{2} /$ perovskite interface is intimately responsible for the hysteresis response of the devices..$^{37,38}$ Before exploring the charge/ion accumulation mechanism in the devices, the key parameters of solar cells such as series resistance $\left(\mathrm{R}_{\mathrm{S}}\right)$, diode ideality factor $(m)$ and dark reverse saturation current $\left(\mathrm{J}_{0}\right)$ were calculated. A series resistance of $13.5 \Omega$ and $12 \Omega$ were obtained from the real intercept in the high frequency region of complex impedance for $\mathrm{MAPbI}_{3}(\mathrm{~s})$ and $\mathrm{MAPbI}_{3}(\mathrm{~m})$ based perovskite solar cells, respectively (see Figure $S 9$ ). A comparable value of $R_{S}$ and FF along with the similar structural property (XRD) signifies that $\mathrm{MAPbI}_{3}(\mathrm{~m})$ exhibits structural and electrical properties similar to $\mathrm{MAPbI}_{3}(\mathrm{~s})$. The effective ideality factor $\left(\mathrm{m}_{\text {eff }}\right)$ as a function of applied bias is shown in Figure 2b. 

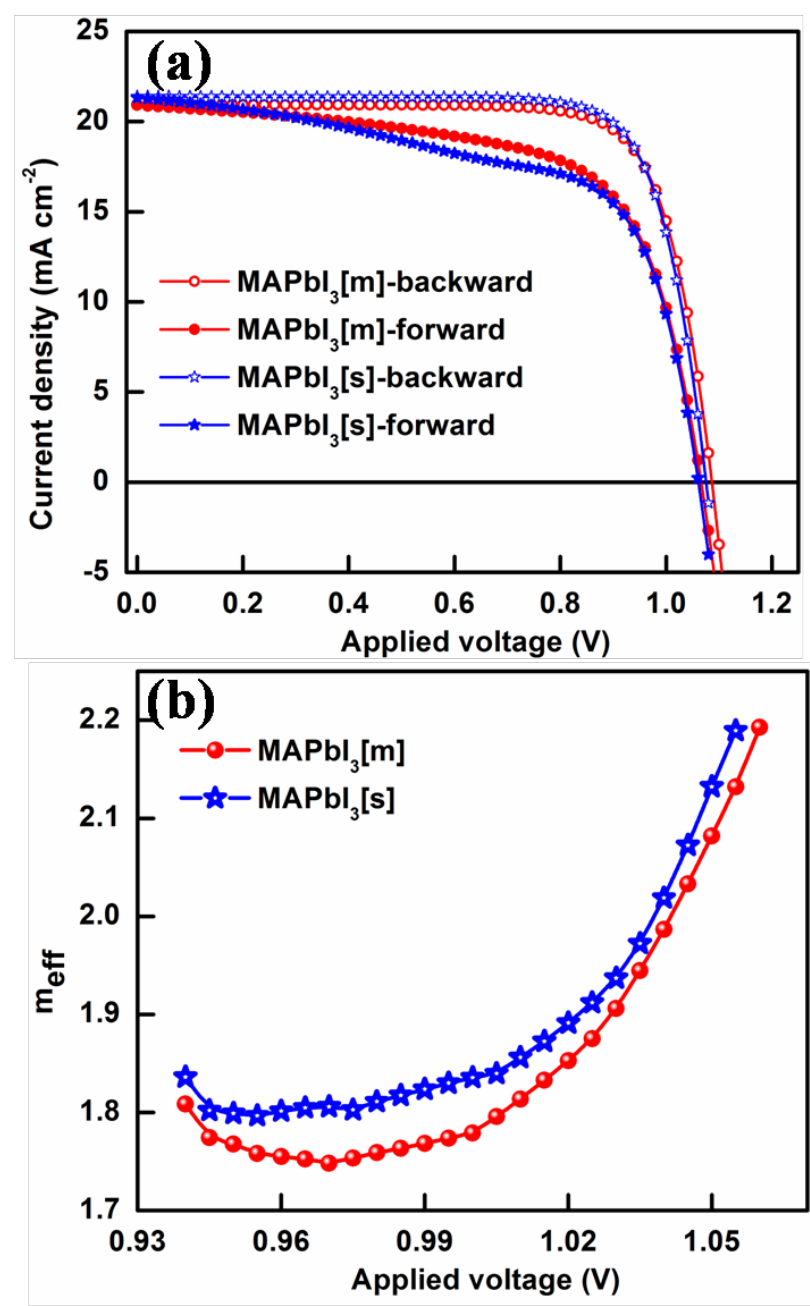

Figure 2. $J-V$ characteristics and ideality factors of perovskite solar cells. (a) Current density versus voltage characteristics of $\mathrm{MAPbI}_{3}(\mathrm{~s})$ and $\mathrm{MAPbI}_{3}(\mathrm{~m})$ based devices under 1 sun (1000 $\mathrm{Wm}^{-2} \mathrm{AM} 1.5$ illumination) at a scan speed of $0.01 \mathrm{~V} \mathrm{~s}^{-1}$ in the backward and forward direction. (b) Effective ideality factor as a function of applied bias for $\mathrm{MAPbI}_{3}(\mathrm{~s})$ and $\mathrm{MAPbI}_{3}(\mathrm{~m})$ based devices.

The saturated response of $\mathrm{m}_{\text {eff }}$ for the investigated devices appears in the bias range of 0.93 to $1.02 \mathrm{~V}$ and corresponds to the average value of $\mathrm{m}_{\text {eff }}=1.8$ for $\operatorname{MAPbI}_{3}(\mathrm{~s})$ and $\mathrm{m}_{\text {eff }}=1.76$ for $\mathrm{MAPbI}_{3}(\mathrm{~m})$. The value of $\mathrm{m}_{\text {eff }}$ close to 2 can be attributed to the dominance of Shockley-Read- 
Hall recombination (SRH). ${ }^{39}$ By taking these experiementally determined values of $\mathrm{m}_{\text {eff }}, \mathrm{J}_{0}$ values of $8.33 \times 10^{-13}$ and $4.89 \times 10^{-13} \mathrm{~A} / \mathrm{cm}^{2}$ are obtained for $\mathrm{MAPbI}_{3}(\mathrm{~s})$ and $\mathrm{MAPbI}_{3}(\mathrm{~m})$ based solar cells, respectively.

Considering the fact that hysteresis phenomena may be related to the interfacial charge accumulation and is more prominent in $\operatorname{MAPbI}_{3}(\mathrm{~s})$ than $\operatorname{MAPbI}_{3}(\mathrm{~m})$ devices, impedance spectroscopy (IS) measurements were performed at zero bias under dark and illumination to investigate the ionic and electronic charge accumulation. As shown in Figure S8, Nyquist spectra in the dark exhibit a high frequency semicircle related to the electronic transport followed by the low frequency line due to ionic diffusion or ionic charge accumulation. ${ }^{40}$ We find that the Nyquist spectra of the studied devices drastically change under illumination and can be characterized by two distinguished semicircles in the high and low frequency regime. The capacitance that corresponds to ionic and electronic accumulation as a function of frequency can be obtained from the imaginary impedance and is shown in Figure 3. The capacitance in the range of $0.05 \mu \mathrm{F} / \mathrm{cm}^{2}$ to $0.1 \mu \mathrm{F} / \mathrm{cm}^{2}$ at high frequency is due to the electronic polarization and/or geometrical capacitance of perovskite, whereas the observed capacitance values of $1 \mu \mathrm{F} / \mathrm{cm}^{2}$ and $10 \mu \mathrm{F} / \mathrm{cm}^{2}$ for $\mathrm{MAPbI}_{3}(\mathrm{~m})$ and $\mathrm{MAPbI}_{3}(\mathrm{~s})$ at low frequency are due to the electrode polarization caused by ionic accumulation (under dark). ${ }^{41}$ 

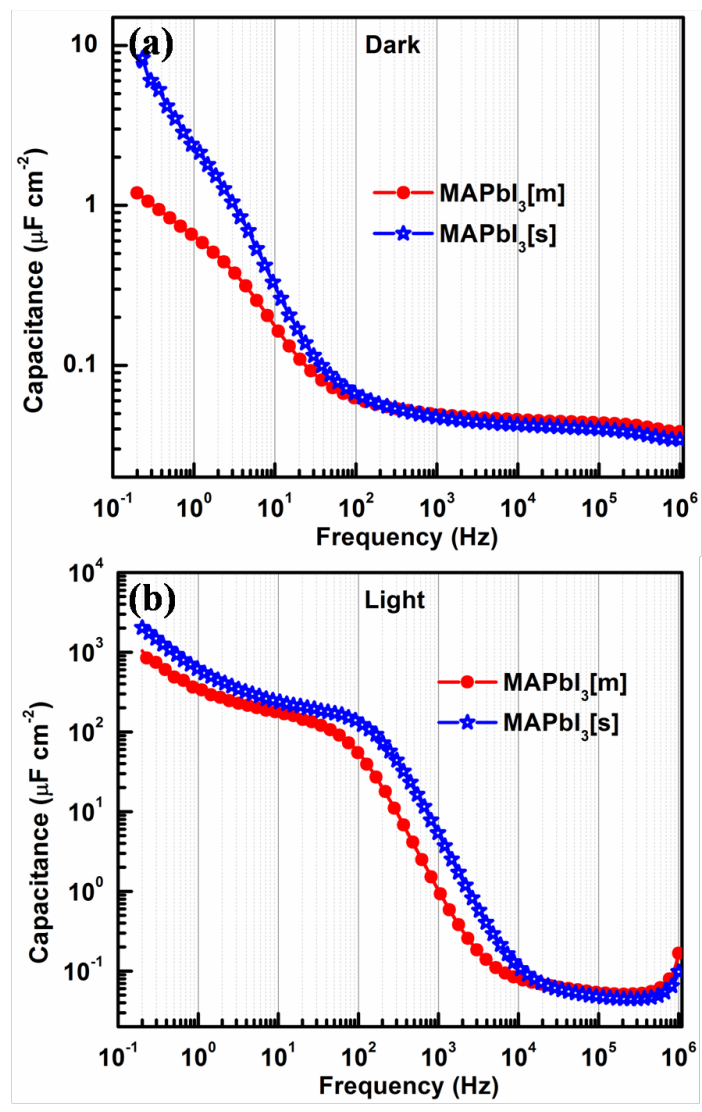

Figure 3. Frequency response of perovskite solar cells. Capacitance versus frequency spectra of $\mathrm{MAPbI}_{3}(\mathrm{~s})$ and $\mathrm{MAPbI}_{3}(\mathrm{~m})$ based devices under (a) dark and (b) light at the short circuit condition in the frequency range of $200 \mathrm{mHz}$ to $1 \mathrm{MHz}$.

The higher value of capacitance at low frequency indicates the presence of more numerous electronic defect states at the interfaces. Contreras et al. have found that the dipole moment of the $\mathrm{MA}^{+}$is likely to determine its interaction with electron transport layer (ETL) that corresponds to the low frequency capacitance..$^{40}$ Therefore, in the present case of having the same absorber perovskite layer, but synthesized by different routes, we speculate that the lower interfacial area and/or weaker chemical interaction between $\mathrm{MAPbI}_{3}(\mathrm{~m})$ absorber layer with $\mathrm{TiO}_{2}$ is likely to determine the interfacial capacitance. These results illustrate that the interfacial capacitance of 
ETL/perovskite absorber layer along with the dipole moment of cations also depends upon the used synthesis route. Furthermore, the low frequency capacitance response under illumination increases to a value of $2 \mathrm{mF} / \mathrm{cm}^{2}$ and $0.9 \mathrm{mF} / \mathrm{cm}^{2}$ for $\mathrm{MAPbI}_{3}(\mathrm{~s})$ and $\mathrm{MAPbI}_{3}(\mathrm{~m})$ devices, respectively. Such high values of capacitance can not only originate from the ionic contribution, but also arise from electronic accumulation. ${ }^{35,41}$ Almost the same extent of change in the low frequency capacitance under illumination is observed. This reinforces the notion that illumination induces similar modifications at the ETL/perovskite interface. The analysis of $J-V$ characteristics with scan direction and capacitance vs frequency for $\mathrm{MAPbI}_{3}(\mathrm{~s})$ and $\mathrm{MAPbI}_{3}(\mathrm{~m})$ based devices reveals that accumulation of ionic charges at the interface (ETL/perovskite) affects the extent of hysteresis. In this regard, it has been shown that the formation of an electronic charge accumulation layer at open circuit causes a slight upward band bending with respect to the vacuum level and the net $\mathrm{V}_{\mathrm{OC}}$ of device can be determined from the contributions of electrostatic potential and built-in potential. ${ }^{42}$ Moreover, the accumulation of photogenerated charge carriers can also promote the recombination process. Therefore, an interplay between higher open circuit voltage and recombination process always exist in the PSCs.

In order to investigate the influence of formed accumulation zone at the vicinity of interface on the transport and recombination phenomena in $\mathrm{MAPbI}_{3}(\mathrm{~s})$ and $\mathrm{MAPbI}_{3}(\mathrm{~m})$ based solar cells, intensity-modulated photocurrent and photovoltage (IMPS and IMVS) spectroscopy measurements were performed. Figure $4 \mathrm{a}-\mathrm{b}$ shows the imaginary IMPS vs frequency as a function of bias for $\mathrm{MAPbI}_{3}(\mathrm{~s})$ and $\mathrm{MAPbI}_{3}(\mathrm{~m})$ devices, respectively. Here the bias refers to photovoltage generated (open circuit potential) during various illumination intensities (from 0.5 to 1 Sun). 

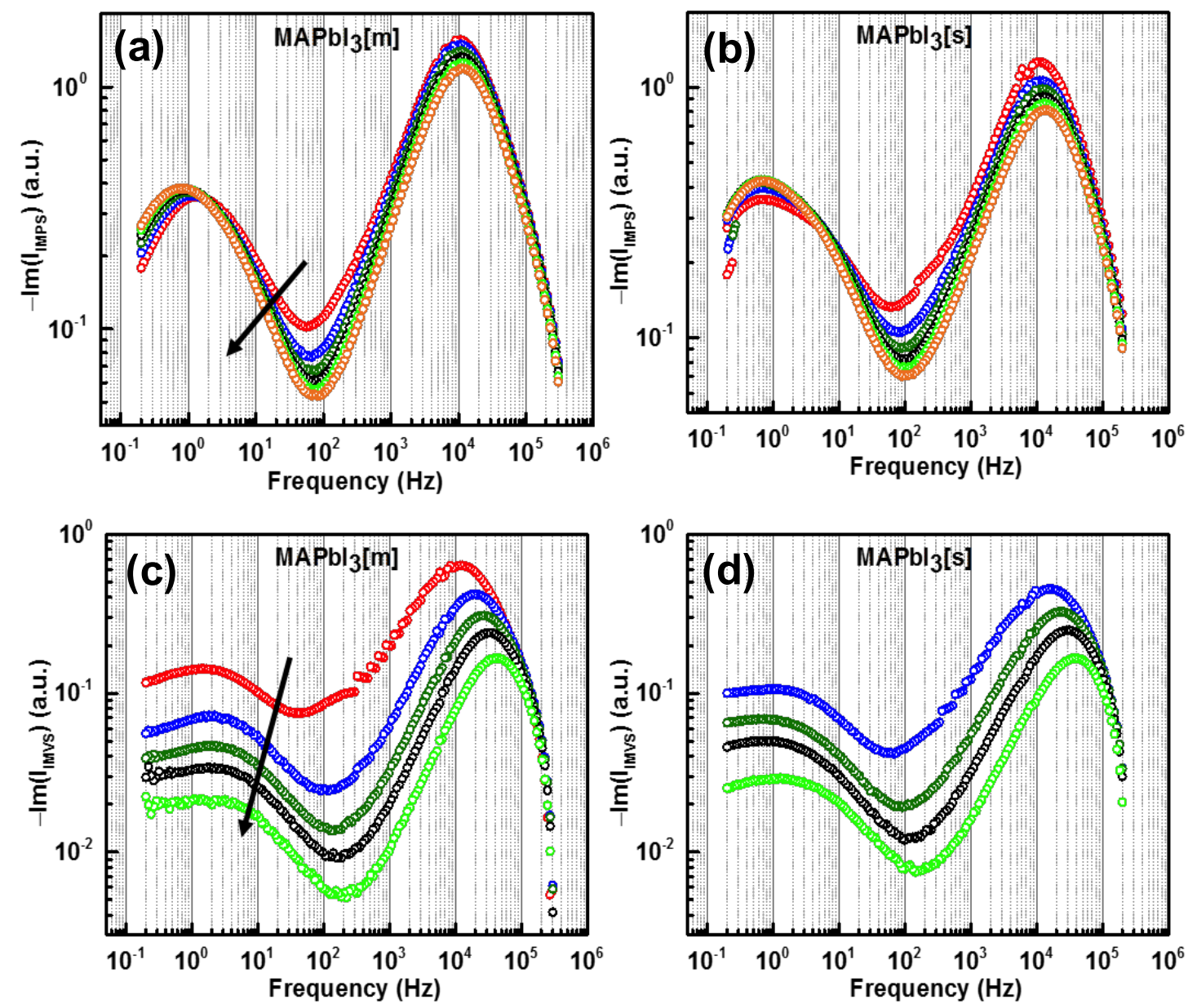

Figure 4. Frequency response of perovskite solar cells at short circuit and open circuit conditions. (a) and (b) IMPS measurements of a $\mathrm{MAPbI}_{3}(\mathrm{~m})$ and $\mathrm{MAPbI}_{3}(\mathrm{~s})$ based perovskite solar cells in the frequency range of $200 \mathrm{mHz}$ to $300 \mathrm{kHz}$ under short circuit condition at

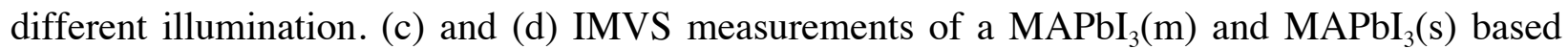
perovskite solar cells under open circuit condition at different illumination intensities. The arrow shows the increase in illumination and corresponding voltage across cells.

Recent studies on the IMPS response of perovskite solar cells show that the peak at high frequency $10^{4} \mathrm{~Hz}$ can be attributed to the charge transport by the perovskite absorber layer, 
whereas the peak at low frequency $\sim 1 \mathrm{~Hz}$ has been associated with the ionic movement. ${ }^{43,44,45}$ From the high frequency response centered at $\sim 10^{4} \mathrm{~Hz}$ with weak bias dependence, it could be expected that the transport and diffusion across the absorber layer or absorber/HTM interface in the studied devices are similar and cannot limit their performance. Thus, it becomes important to recognize the physical origin of high frequency spectra before assigning to the transport phenomena; thereby taking the values of $\mathrm{R}_{\mathrm{S}}$ and $\tau_{\mathrm{HF}}$ (from high frequency intercept of IS), the obtained capacitance equivalent to geometrical capacitance $\left(\mathrm{C}_{\mathrm{g}}\right)$ signifies $\tau_{\mathrm{HF}}$ to be dominated by $\mathrm{C}_{\mathrm{g}}$. The low frequency component with the maximum in the range of $800 \mathrm{mHz}$ to $1 \mathrm{~Hz}$ for $\mathrm{MAPbI}_{3}(\mathrm{~s})$ corresponds to the time constant of $0.18 \mathrm{~s}$ and diffusion coefficient of $9.4 \times 10^{-10} \mathrm{~cm}^{2} \mathrm{~s}^{-}$ 1. Similarly, the low frequency component with the maximum in the range of $1 \mathrm{~Hz}$ to $3 \mathrm{~Hz}$ for $\mathrm{MAPbI}_{3}(\mathrm{~m})$ corresponds to the time constant of $0.10 \mathrm{~s}$ and diffusion coefficient of $1.7 \times 10^{-9} \mathrm{~cm}^{2} \mathrm{~s}^{-}$ 1. The net effective charge carrier transport across the solar cells measured by current transient technique at short circuit condition is shown in the Figure S10. The shortened current decay response in $\mathrm{MAPbI}_{3}(\mathrm{~s})$ illustrates faster charge transport than in $\mathrm{MAPbI}_{3}(\mathrm{~m})$. This means that for almost the same absorption coefficient and charge transport at $\mathrm{TiO}_{2}$ /perovskite interface, the lower charge transport into the absorber layer limits the photocurrent observed in the $\mathrm{MAPbI}_{3}(\mathrm{~m})$ device. Figure 4c-d shows the IMVS response of both the solar cells in frequency domain as a function of bias near the open circuit voltage. Interestingly, the low and high frequency response of IMVS exhibits an opposite behavior in comparison to the IMPS response. We observe the bias dependence in the high frequency spectra region and insignificant bias dependence in the low frequency spectra region. This fact suggests the difference in the recombination mechanism depending upon the applied bias and material property. In both the solar cells, the low frequency peak with the maxima at $1 \mathrm{~Hz}$ corresponds to the time response of $0.16 \mathrm{~s}$. A time constant of this 
order cannot be considered as carrier lifetime, rather it may be speculated to be the recombination at the surface trap states, where the overall recombination takes place between the surface captured electron and hole.

The life time obtained from the high frequency as a function of applied bias are presented in Figure S11. An inverse proportionality between the life time and bias is obtained. It is important to note that the capacitance in the frequency range $>10^{4} \mathrm{~Hz}$ under dark and illumination condition remains unchanged due to dominance of geometrical capacitance rather than the chemical; therefore the obtained characteristic life time has no physical meaning. On the basis of the above mentioned analysis, it is found that the most significant part of charge transport and recombination occurs at the $\mathrm{TiO}_{2}$ /perovskite interface, which is almost similar for the studied devices. Thermal admittance spectroscopy was used to identify the difference between the two synthesis routes in terms of defect energy level and their defect density. This measurement allows to monitor the interfacial electronic defect states, which causes an electron and hole recombination. The capacitance vs frequency plot under dark conditions in the frequency range of $200 \mathrm{mHz}$ to $1 \mathrm{MHz}$ as a function of temperature were measured to obtain the defect activation energy. The defect activation energy was calculated by fitting the Arrhenius plot with the expression $E_{\omega}=K_{B} T \ln \left(\omega_{0} / \omega\right)$ where, $K_{B}, T$ are Boltzmann's constant and temperature, and $\omega_{0}$ is the attempt to escape frequency. The activation energy of $17 \mathrm{meV}$ and $21 \mathrm{meV}$ were calculated for $\mathrm{MAPbI}_{3}(\mathrm{~s})$ and $\mathrm{MAPbI}_{3}(\mathrm{~m})$ based devices, which is close to the value quoted by Marco et al. ${ }^{46}$ as well as Meloni and Heo et al. ${ }^{47,48}$ It has been shown that the iodine vacancies at this energy level are most detrimental for charge trapping and recombination. The density of traps or defects were calculated by the equation $N_{t}=\left(-V_{b i} / q W\right)\left(\frac{\partial c}{\partial \omega}\right) \omega / K_{B} T$ where $V_{b i}$ and $W$ are the built-in potential and depletion width. The density of defect states shown in Figure 5 depicts a 
large variation in the order of $N_{t}$ from $10^{16}$ to $10^{19} \mathrm{~cm}^{-3} \mathrm{eV}^{-1}$ with the corresponding energy levels from 0.1 to $0.6 \mathrm{eV}$. The deeper defect energy level with the maximum at $0.48 \mathrm{eV}$ for $\mathrm{MAPbI}_{3}(\mathrm{~s})$ and $0.52 \mathrm{eV}$ in $\mathrm{MAPbI}_{3}(\mathrm{~m})$ devices can be ascribed to the movement of iodine vacancies, as was observed by Eames et al. ${ }^{49}$ We find that the defect density at deeper defect levels mostly located on the surface of perovskite absorber layer is nearly an order of magnitude lower in $\operatorname{MAPbI}_{3}(\mathrm{~m})$ based device. Thus, a significant lower defect density is consistent with the lower hysteresis observed in $\mathrm{MAPbI}_{3}(\mathrm{~m})$ based device and with an overall advantage of higher $\mathrm{V}_{\mathrm{OC}}$.
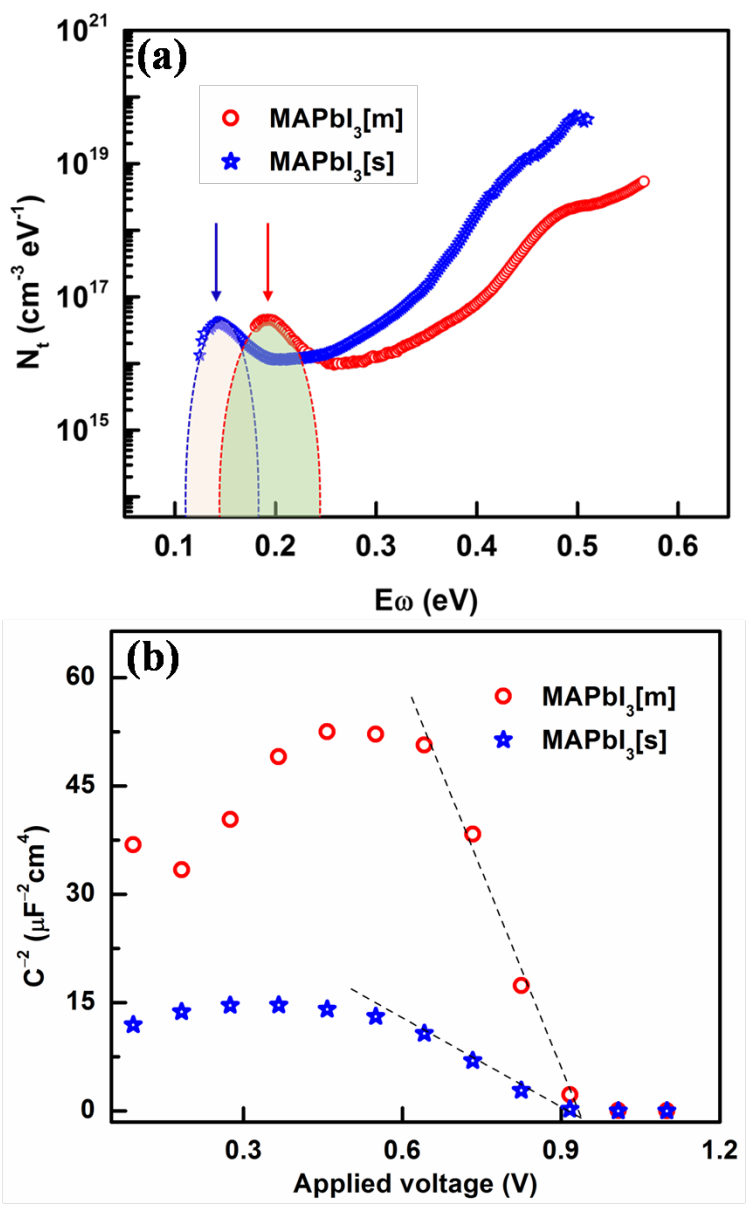

Figure 5. (a) Defect densities distribution in $\mathrm{MAPbI}_{3}(\mathrm{~m})$ and $\mathrm{MAPbI}_{3}(\mathrm{~s})$ based perovskite solar cells deduced from capacitance vs frequency at $300 \mathrm{~K}$ plotted vs. energy. The lower and higher energies corresponds to an shallow and deeper defect energy level. (b) Mott-Schottky plot 
in $\mathrm{MAPbI}_{3}(\mathrm{~m})$ and $\mathrm{MAPbI}_{3}(\mathrm{~s})$ based perovskite solar cells. Capacitance was measured at $2 \mathrm{kHz}$ oscillation frequency with $20 \mathrm{mV}$ AC amplitude.

However, a similar integrated defect density of the order of $10^{16} \mathrm{~cm}^{-3}$ with the maxima at 0.17 $\mathrm{eV}$ and $0.21 \mathrm{eV}$ were obtained for $\mathrm{MAPbI}_{3}(\mathrm{~s})$ and $\mathrm{MAPbI}_{3}(\mathrm{~m})$ based devices, respectively. Figure 5b shows the Mott Schottky (MS) plot at $2 \mathrm{kHz}$ in the forward scan for the studied devices. It should be noted here that the shown plot at bias $>0.6 \mathrm{~V}$ is not from the depletion capacitance, but from interfacial surface capacitance $\left(C_{S}\right)$. Recently, it has been shown that the defect density in the perovskite absorber layer is detected by MS only if the absorber layer contains a higher defect density than the surface defects. ${ }^{50}$ Using $\varepsilon=30,{ }^{50}$ defect densities of 2.76 $\times 10^{18}$ and $5.57 \times 10^{17} \mathrm{~cm}^{-3}$ were obtained for $\mathrm{MAPbI}_{3}(\mathrm{~s})$ and $\mathrm{MAPbI}_{3}(\mathrm{~m})$ devices, respectively. These values are also consistent with the evidence for deeper energy levels (see Figure 5a). This observation means that the use of $\mathrm{MAPbI}_{3}$ mechanoperovskite for the thin film preparation can efficiently reduce the interfacial defect density explaining the lower hysteresis. Moreover, the built in potential were calculated by taking the intercept at $\mathrm{X}$-axis and a comparable values of $\sim 0.95 \mathrm{~V}$ is obtained for each of device.

\section{CONCLUSION}

In conclusion, we developed a procedure to fabricate efficient PSCs based on mechanochemically synthesized $\mathrm{MAPbI}_{3}$. The perovskite thin film processed via fast one-step deposition-crystallization method exhibited uniform, smooth and complete surface coverage with a relatively large crystal grains. The cell derived from $\mathrm{MAPbI}_{3}(\mathrm{~m})$ and $\mathrm{MAPbI}_{3}(\mathrm{~s})$ showed a stabilized PCE of $16.8 \%$ and $17.1 \%$ under maximum power point tracking, respectively. In both 
devices, the value of the effective ideality factor $m_{\text {eff }}$ close to 2 was attributed to Shockley-ReadHall recombination (SRH). The analysis of $J-V$ characteristics with scan direction and capacitance vs frequency of $\mathrm{MAPbI}_{3}(\mathrm{~s})$ device reveals that accumulation of excess ionic charges at the interface (ETL/perovskite) affects the extent of hysteresis. It was also found that the defect density on the surface of perovskite absorber layer is nearly an order of magnitude lower in $\mathrm{MAPbI}_{3}(\mathrm{~m})$ as that of $\mathrm{MAPbI}_{3}(\mathrm{~s})$ based device that could also be correlated with the observed lower hysteresis. Hence, we believe that the lower hysteresis in $\mathrm{MAPbI}_{3}(\mathrm{~m})$ based device is facilitation of better quality of the perovskite that reduces recombination at interfaces, as shown by the higher $\mathrm{V}_{\mathrm{OC}}$ value.

Our result demonstrates that the direct thin film crystallization from the mechanoperovskite is a promising method for achieving solar cells with less hysteresis. This study also opens up new possibilities for the efficient and sustainable synthesis of other hybrid perovskites.

\section{EXPERIMENTAL SECTION}

Materials and Methods. Polycrystalline perovskite powders were synthesized by grinding an organic salt MAI (DyeSol) and $\mathrm{PbI}_{2}$ (TCI) in an electric ball mill (Retsch Ball Mill MM-200, agat grinding jar with a volume of $10 \mathrm{ml}$ and 1 agat ball, diameter size $10 \mathrm{~mm}$ ) for $30 \mathrm{~min}$ at $30 \mathrm{~Hz} .0 .159 \mathrm{~g}$ of MAI (1 mmol $)$ and $0.461 \mathrm{~g}(1,00 \mathrm{mmol})$ of $\mathrm{PbI}_{2}$ were mixed to prepare the $\mathrm{MAPbI}_{3}$ black powder. The synthesis was conducted in glove box under an argon atmosphere.

Solar cell device fabrication. The devices were prepared in line with our previous report ${ }^{28}$ and were made of a stacking of FTO/compact $\mathrm{TiO}_{2}$-layer/mesoporous $\mathrm{TiO}_{2} /$ perovskite/ spiro-MeOTAD/Au. The 1.4 $\mathrm{M}$ stock solution of $\mathrm{MAPbI}_{3}$ mechanoperovskite particles was prepared by dissolving grounded powder in anhydrous DMSO by vigorous stirring at $60^{\circ} \mathrm{C}$. Perovskite stock reference solution in anhydrous DMSO was prepared from $\mathrm{PbI}_{2}(0.64 \mathrm{~g})$ by mixing it with MAI $(0.22 \mathrm{~g})$ in a molar ratio of 1 : 
1 by vigorous stirring at $60^{\circ} \mathrm{C}$. The perovskite solutions were deposited by spin coating in a two-step program at 1000 and $6000 \mathrm{rpm}$ for 10 and $20 \mathrm{~s}$ respectively. During the second step, $100 \mu \mathrm{L}$ of chlorobenzene was poured on the spinning substrate $10 \mathrm{~s}$ prior to the end of the program. The substrates were then annealed at $100{ }^{\circ} \mathrm{C}$ for $30 \mathrm{~min}$ in a dry box. Hole transporting material (HTM) solution was prepared by dissolving $74 \mathrm{mg}$ spiro-MeOTAD in $1 \mathrm{ml}$ chlorobenzene and additionally mixing it with 17.5 $\mu \mathrm{L}$ of lithium bis(trifluoromethylsulphonyl)imide (stock solution Li-TFSI $520 \mathrm{mg} \cdot \mathrm{mL}-1$ in acetonitrile), $28.8 \mu \mathrm{L}$ tert-butylpyridine and $29 \mu \mathrm{l}$ of $\operatorname{tris}(2-(1 \mathrm{H}-$ pyrazol-1-yl)-4-tert-butylpyridine)cobalt(III) bis(trifluoromethylsulphonyl) imide (stock solution FK 209, $300 \mathrm{mg} \cdot \mathrm{ml}-1$ in acetonitrile). HTM was deposited on top of the perovskite layer by spin coating at $4000 \mathrm{rpm}$ for $20 \mathrm{~s}$. Finally, $80 \mathrm{~nm}$ of gold top electrode was thermally evaporated under high vacuum.

Device characterization. The $J-V$ characteristics of the devices were measured under $100 \mathrm{~mW} / \mathrm{cm}^{2}$ conditions using a $450 \mathrm{~W}$ Xenon lamp (Oriel), as a light source, equipped with a Schott K113 Tempax sunlight filter (Praezisions Glas \& Optik $\mathrm{GmbH}$ ) to match the emission spectra to the AM1.5G standard in the region of 350-750 $\mathrm{nm}$. The current-voltage characteristics of the devices were obtained by applying external potential bias to the cell while recording the generated photocurrent using a Keithley (Model 2400) digital source meter. The J-V curves of all devices were measured by masking the active area with a metal mask of area $0.16 \mathrm{~cm}^{2}$. AC measurements were performed using a potentiostat Biologic SP300 equipped with a frequency response analyser. IS measurements were performed in the DC bias range of 0 to open circuit voltage with an AC perturbation signal of $10 \mathrm{mV}$ in the frequency range of $1 \mathrm{~Hz}$ to100 kHz. IMVS and IMPS measurements were done by using a frequency response analyzer (FRA) combined with Bio-Logic SP300 potentiostat. The modulation current was set to be $10 \%$ of the DC background illumination intensity. The modulated cool white-LED array $(12 \mathrm{~V}, 10 \mathrm{~W})$ light source was driven by a galvanostatic mode of Biologic SP-300. 


\section{ASSOCIATED CONTENT}

\section{Supporting Information}

The Supporting Information is available free of charge on the ACS Publications website.

PXRD pattern of $\mathrm{MAPbI}_{3}$ films; grain size distribution histograms; SEM cross section images; $J-V$ characteristics of devices under dark; Nyquist spectra of devices under dark and light at the zero bias; statistics histogram, current transient characteristics of devices under short circuit condition; high frequency extracted life time as a function of applied bias of devices. (PDF)

\section{AUTHOR INFORMATION}

\section{Corresponding Author}

E-mail:dprochowicz@ichf.edu.pl,lewin@ch.pw.edu.pl,michael.graetzel@epfl.ch

\section{Author Contributions}

The manuscript was written through contributions of all authors.

$\dagger$ These authors contributed equally.

\section{ACKNOWLEDGMENT}

D. P. acknowledges support from the co-funded Marie Skłodowska Curie fellowship, H2020 Grant agreement no. 707168. M. S. acknowledges support from the co-funded Marie Skłodowska Curie fellowship, H2020 Grant agreement no. 665667. M. S, J. L. and M. G. thank funding from the European Union's Horizon 2020 programme, through a FET Open research and innovation action under grant agreement no. 687008 . 


\section{REFERENCES}

(1) Park, N.-G. Perovskite Solar Cells: An Emerging Photovoltaic Technology. Mater. Today 2015, 18, 65-72.

(2) Zhao, Y.; Zhu, K. Organic-Inorganic Hybrid Lead Halide Perovskites for Optoelectronic and Electronic Applications. Chem. Soc. Rev. 2016, 45, 655-689.

(3) Kojima, A.; Teshima, K.; Shirai, Y.; Miyasaka, T. Organometal Halide Perovskites as Visible-Light Sensitizers for Photovoltaic Cells. J. Am. Chem. Soc. 2009, 131, 6050-6051.

(4) Li, X.; Bi, D.; Yi, C.; Décoppet, J. D.; Luo, J.; Zakeeruddin, S. M.; Hagfeldt, A.; Grätzel, M. A Vacuum Flash-Assisted Solution Process for High-Efficiency Large-Area Perovskite Solar Cells. Science, 2016, 353, 58-62.

(5) Saliba, M.; Matsui, T.; Domanski, K.; Seo, J.-Y.; Ummadisingu, A.; Zakeeruddin, S. M.; Correa Baena, J.-P.; Tress, W. R.; Abate, A.; Hagfeldt, A.; Gratzel, M. Incorporation of Rubidium Cations into Perovskite Solar Cells Improves Photovoltaic Performance. Science 2016, 354, 206-209.

(6) Yang, W. S.; Park, B.-W.; Jung, E. H.; Jeon, N. J.; Kim, Y. C.; Lee, D. U.; Shin, S. S.;

Seo, J.; Kim, E. K.; Noh, J. H.; Seok, S. I. Iodide Management in Formamidinium-Lead-HalideBased Perovskite Layers for Efficient Solar Cells. Science 2017, 356, 1376-1379.

(7) Im, J.-H.; Kim, H.-S.; Park, N.-G. Morphology-Photovoltaic Property Correlation in Perovskite Solar Cells: One-step Versus Two-Step Deposition of $\mathrm{CH}_{3} \mathrm{NH}_{3} \mathrm{PbI}_{3}$. APL Mater. 2014, 2, 081510 . 
(8) Sharenko, A.; Toney, M. F. Relationships between Lead Halide Perovskite Thin-Film Fabrication, Morphology, and Performance in Solar Cells. J. Am. Chem. Soc. 2016, 138, 463470.

(9) Song, T.-B.; Chen, Q.; Zhou, H.; Jiang, C.; Wang, H.-H.; Yang, Y. (Michael); Liu, Y.; You, J.; Yang, Y. Perovskite Solar Cells: Film Formation and Properties. J. Mater. Chem. A 2015, 3, 9032-9050.

(10) Eperon, G. E.; Burlakov, V. M.; Docampo, P.; Goriely, A.; Snaith, H. J. Morphological Control for High Performance, Solution-Processed Planar Heterojunction Perovskite Solar Cells. Adv. Funct. Mater. 2014, 24, 151-157.

(11) Snaith, H. J.; Abate, A.; Ball, J. M.; Eperon, G. E.; Leijtens, T.; Noel, N. K.; Stranks, S. D.; Wang, J. T.-W.; Wojciechowski, K.; Zhang, W. Anomalous Hysteresis in Perovskite Solar Cells. J. Phys. Chem. Lett. 2014, 5, 1511-1515.

(12) Shao, Y.; Xiao, Z.; Bi, C.; Yuan, Y.; Huang, J. Origin and Elimination of Photocurrent Hysteresis by Fullerene Passivation in $\mathrm{CH} 3 \mathrm{NH} 3 \mathrm{PbI} 3$ Planar Heterojunction Solar Cells. Nat. Commun. 2014, 5, 5784.

(13) Liu, S.; Zheng, F.; Koocher, N. Z.; Takenaka, H.; Wang, F.; Rappe, A. M. Ferroelectric Domain Wall Induced Band Gap Reduction and Charge Separation in Organometal Halide Perovskites. J. Phys. Chem. Lett. 2015, 6, 693-699.

(14) Rothmann, M. U.; Li, W.; Zhu, Y.; Bach, U.; Spiccia, L.; Etheridge, J.; Cheng, Y.-B. Direct Observation of Intrinsic Twin Domains in Tetragonal $\mathrm{CH}_{3} \mathrm{NH}_{3} \mathrm{PbI}_{3}$. Nat. Commun. 2017, 8,14547 . 
(15) Stranks, S. D.; Eperon, G. E.; Grancini, G.; Menelaou, C.; Alcocer, M. J.; Leijtens, T.; Herz, L. M.; Petrozza, A.; Snaith, H. J. Electron-hole Diffusion Lengths Exceeding 1 Micrometer in an Organometal Trihalide Perovskite Absorber. Science 2013, 342, 341-344.

(16) Dong, Q. F.; Fang, Y. J.; Shao, Y. C.; Mulligan, P.; Qiu, J.; Cao, L.; Huang, J. S. Solar Cells. Electron-hole Diffusion Lengths $>175 \mu \mathrm{m}$ in Solution-Grown $\mathrm{CH}_{3} \mathrm{NH}_{3} \mathrm{PbI}_{3}$ Single Crystals. Science 2015, 347, 967-970.

(17) Lee, M. M.; Teuscher, J.; Miyasaka, T.; Murakami, T. N.; Snaith, H. J. Efficient Hybrid Solar Cells Based on Meso-Superstructured Organometal Halide Perovskites. Science 2012, 338, 643-647.

(18) Kim, H.-S.; Lee, C.-R.; Im, J.-H.; Lee, K.-B.; Moehl, T.; Marchioro, A.; Moon, S.-J.; Humphry-Baker, R.; Yum, J.-H.; Moser, J. E.; Graetzel, M.; Park, N.-G. Lead Iodide Perovskite Sensitized All-Solid-State Submicron Thin Film Mesoscopic Solar Cell with Efficiency Exceeding 9\%. Sci.Rep. 2012, 2, 591.

(19) Liu, M.; Johnston, M. B.; Snaith, H. J. Efficient Planar Heterojunction Perovskite Solar Cells by Vapour Deposition. Nature 2013, 501, 395-398.

(20) Jeon, N. J.; Noh, J. H.; Kim, Y. C.; Yang, W. S.; Ryu, S.; Seok, S. I. Solvent Engineering for High-Performance Inorganic-Organic Hybrid Perovskite Solar Cells. Nat. Mater. 2014, 13, 897-903.

(21) Xiao, M.; Huang, F.; Huang, W.; Dkhissi, Y.; Zhu, Y.; Etheridge, J.; Gray-Weale, A.; Bach, U.; Cheng, Y. B.; Spiccia, L. A Fast Deposition-Crystallization Procedure for Highly 
Efficient Lead Iodide Perovskite Thin-Film Solar Cells. Angew. Chem. Int. Ed. 2014, 53, 98989903.

(22) Chueh, C.-C.; Liao, C.-Y.; Zuo, F.; Williams, S. T.; Liang, P.-W.; Jen, A. K.-Y. The Roles of Alkyl Halide Additives in Enhancing Perovskite Solar Cell Performance. J. Mater. Chem. A 2015, 3, 9058-9062.

(23) Zuo, C.; Ding, L. An 80.11\% FF Record Achieved for Perovskite Solar Cells by Using the $\mathrm{NH}_{4} \mathrm{Cl}$ Additive. Nanoscale 2014, 6, 9935-9938.

(24) Jacobsson, T. J.; Correa-Baena, J.-P.; Halvani Anaraki, E.; Philippe, B.; Stranks, S. D.; Bouduban, M. E. F.; Tress, W.; Schenk, K.; Teuscher, J.; Moser, J.-E.; Rensmo, H.; Hagfeldt, A. Unreacted $\mathrm{PbI}_{2}$ as a Double-Edged Sword for Enhancing the Performance of Perovskite Solar Cells. J. Am. Chem. Soc. 2016, 138, 10331-10343.

(25) Son, D.-Y.; Lee, J.-W.; Choi, Y. J.; Jang, I.-H.; Lee, S.; Yoo, P. J.; Shin, H.; Ahn, N.; Choi, M.; Kim, D.; Park, N.-G. Self-formed Grain Boundary Healing Layer for Highly Efficient $\mathrm{CH}_{3} \mathrm{NH}_{3} \mathrm{PbI}_{3}$ Perovskite Solar Cells. Nat. Energy 2016, 1, 16081.

(26) Jiang, Y.; Juarez-Perez, E. J.; Ge, Q.; Wang, S.; Leyden, M. R.; Ono, L. K.; Raga, S. R.; $\mathrm{Hu}$, J.; Qi, Y. Post-annealing of $\mathrm{MAPbI}_{3}$ Perovskite Films with Methylamine for Efficient Perovskite Solar Cells. Mater. Horiz. 2016, 3, 548-555.

(27) Yen, H.-J.; Liang, P.-W.; Chueh, C.-C.; Yang, Z.; Jen, A. K.-Y.; Wang, H.-L. Large Grained Perovskite Solar Cells Derived from Single-Crystal Perovskite Powders with Enhanced Ambient Stability. ACS Appl. Mater. Interfaces 2016, 8, 14513-14520. 
(28) Prochowicz, D.; Franckevicius, M.; Cieślak, A. M.; Zakeeruddin, S. M.; Graetzel, M.; Lewiński, J. Mechanosynthesis of the Hybrid Perovskite $\mathrm{CH}_{3} \mathrm{NH}_{3} \mathrm{PbI}_{3}$ : Characterization and the Corresponding Solar Cell Efficiency. J. Mater. Chem. A 2015, 3, 20772-20777.

(29) Cao, J.; Jing, X.; Yan, J.; Hu, C.; Chen, R.; Yin, J.; Li, J.; Zheng, N. Identifying the Molecular Structures of Intermediates for Optimizing the Fabrication of High-Quality Perovskite Films. J. Am. Chem. Soc. 2016, 138, 9919-9926.

(30) Baikie, T.; Fang, Y. N.; Kadro, J. M.; Schreyer, M.; Wei, F. X.; Mhaisalkar, S. G.; Graetzel, M.; White, T. J. Synthesis and Crystal Chemistry of the Hybrid Perovskite $\left(\mathrm{CH}_{3} \mathrm{NH}_{3}\right) \mathrm{PbI}_{3}$ for Solid-State Sensitised Solar Cell Applications. J. Mater. Chem. A 2013, 1, $5628-5641$.

(31) Correa-Baena, J.-P.; Anaya, M.; Lozano, G.; Tress, W.; Domanski, K.; Saliba, M.; Matsui, T.; Jacobsson, T. J.; Calvo, M. E.; Abate, A.; Grätzel, M.; Míguez, H.; Hagfeldt, A. Unbroken Perovskite: Interplay of Morphology, Electrooptical Properties, and Ionic Movement. Adv. Mater. 2016, 28, 5031-5037.

(32) Li, G.; Ching, K. L.; Ho, J. Y. L.; Wong, M.; Kwok, H.-S. Identifying the Optimum Morphology in High-Performance Perovskite Solar Cells. Adv. Energy Mater. 2015, 5, 1401775.

(33) Fei, C.; Li, B.; Zhang, R.; Fu, H.; Tian, J.; Cao, G. Highly Efficient and Stable Perovskite Solar Cells Based on Monolithically Grained $\mathrm{CH}_{3} \mathrm{NH}_{3} \mathrm{PbI}_{3}$ Film. Adv. Energy Mater. 2017, 7 , 160217.

(34) Chen, B.; Yang, M.; Priya, S.; Zhu, K. Origin of J-V Hysteresis in Perovskite Solar Cells. J. Phys. Chem. Lett. 2016, 7, 905-917. 
(35) Almora, O.; Aranda, C.; Zarazua, I.; Guerrero, A.; Garcia-Belmonte, G. Noncapacitive Hysteresis in Perovskite Solar Cells at Room Temperature. ACS Energy Lett. 2016, 1, 209-215.

(36) Cao, X.; Li, Y.; Li, C.; Fang, F.; Yao, Y.; Cui, X.; Wei, J. Modulating Hysteresis of Perovskite Solar Cells by a Poling Voltage. J. Phys. Chem. C 2016, 120, 22784-22792.

(37) Levine, I.; Nayak, P. K.; Wang, J. T.-W.; Sakai, N.; Van Reenen, S.; Brenner, T. M.; Mukhopadhyay, S.; Snaith, H. J.; Hodes, G.; Cahen, D. Interface-Dependent Ion Migration/Accumulation Controls Hysteresis in $\mathrm{MAPbI}_{3}$ Solar Cells. J. Phys. Chem. C 2016, $120,16399-16411$.

(38) Wu, B.; Fu, K.; Yantara, N.; Xing, G.; Sun, S.; Sum, T. C.; Mathews, N. Charge Accumulation and Hysteresis in Perovskite-Based Solar Cells: An Electro-Optical Analysis. Adv. Energy Mater. 2015, 5, 1500829.

(39) Agarwal, S.; Nair, P. R. Device Engineering of Perovskite Solar Cells to Achieve Near Ideal Efficiency. Appl. Phys. Lett. 2015, 107, 123901.

(40) Contreras, L.; Idigoras, J.; Todinova, A.; Salado, M.; Kazim, S.; Ahmad, S.; Anta, J. A. Specific Cation Interactions as the Cause of Slow Dynamics and Hysteresis in Dye and Perovskite Solar Cells: A Small-Perturbation Study. Phys. Chem. Chem. Phys. 2016, 18, 3103331042.

(41) Zarazua, I.; Bisquert, J.; Garcia-Belmonte, G. Light-Induced Space-Charge Accumulation Zone as Photovoltaic Mechanism in Perovskite Solar Cells. J. Phys. Chem. Lett. 2016, 7, 525528. 
(42) Gottesman, R.; Lopez-Varo, P.; Gouda, L.; Jimenez-Tejada, J. A.; Hu, J.; Tirosh, S.; Zaban, A.; Bisquert, J. Dynamic Phenomena at Perovskite/Electron-Selective Contact Interface as Interpreted from Photovoltage Decays. Chem 2016, 1, 776-789.

(43) Giordano, F.; Abate, A.; Correa Baena, J. P.; Saliba, M.; Matsui, T.; Im, S. H.; Zakeeruddin, S. M.; Nazeeruddin, M. K.; Hagfeldt, A.; Graetzel, M. Enhanced Electronic Properties in Mesoporous $\mathrm{TiO}_{2}$ via Lithium Doping for High-Efficiency Perovskite Solar Cells. Nat. Commun. 2016, 7, 10379.

(44) Pockett, A.; Eperon, G. E.; Peltola, T.; Snaith, H. J.; Walker, A.; Peter, L. M.; Cameron, P. J. Characterization of Planar Lead Halide Perovskite Solar Cells by Impedance Spectroscopy, Open-Circuit Photovoltage Decay, and Intensity-Modulated Photovoltage/Photocurrent Spectroscopy. J. Phys. Chem. C 2015, 119, 3456-3465.

(45) Dudem, B.; Heo, J. H.; Leem, J. W.; Yu, J. S.; Im, S. H. $\mathrm{CH}_{3} \mathrm{NH}_{3} \mathrm{PbI}_{3}$ Planar Perovskite Solar Cells with Antireflection and Self-Cleaning Function Layers. J. Mater. Chem. A 2016, 4, 7573-75739.

(46) Marco, N. D.; Zhou, H.; Chen, Q.; Sun, P.; Liu, Z.; Meng, L.; Yao, E.-P.; Liu, Y.; Schiffer, A.; Yang, Y. Guanidinium: A Route to Enhanced Carrier Lifetime and Open-Circuit Voltage in Hybrid Perovskite Solar Cells. Nano Lett. 2016, 16, 1009-1016.

(47) Meloni, S.; Moehl, T.; Tress, W.; Franckevičius, M.; Saliba, M.; Lee, Y. H.; Gao, P.; Nazeeruddin, M. K.; Zakeeruddin, S. M.; Rothlisberger, U.; Graetzel, M. Ionic PolarizationInduced Current-Voltage Hysteresis in $\mathrm{CH}_{3} \mathrm{NH}_{3} \mathrm{PbX}_{3}$ Perovskite Solar Cells. Nat. Commun. 2016, 7, 10334. 
(48) Heo, J. H.; Lee, M. H.; Han, H. J.; Patil, B. R.; Yu, J. S.; Im, S. H. Highly Efficient Low Temperature Solution Processable Planar Type $\mathrm{CH}_{3} \mathrm{NH}_{3} \mathrm{PbI}_{3}$ Perovskite Flexible Solar Cells. J. Mater. Chem. A 2016, 4, 1572-1578.

(49) Eamas, C.; Frost, J. M.; Barnes, P. R. F.; O’Regan, B. C.; Walsh, A.; Islam, M. S. Ionic Transport in Hybrid Lead Iodide Perovskite Solar Cells. Nat. Commun. 2015, 6, 7497.

(50) Almora, O.; Aranda, C.; Mas-Marzá, E.; Garcia-Belmonte, G. On Mott-Schottky Analysis Interpretation of Capacitance Measurements in Organometal Perovskite Solar Cells. Appl. Phys. Lett. 2016, 109, 173903

TOC

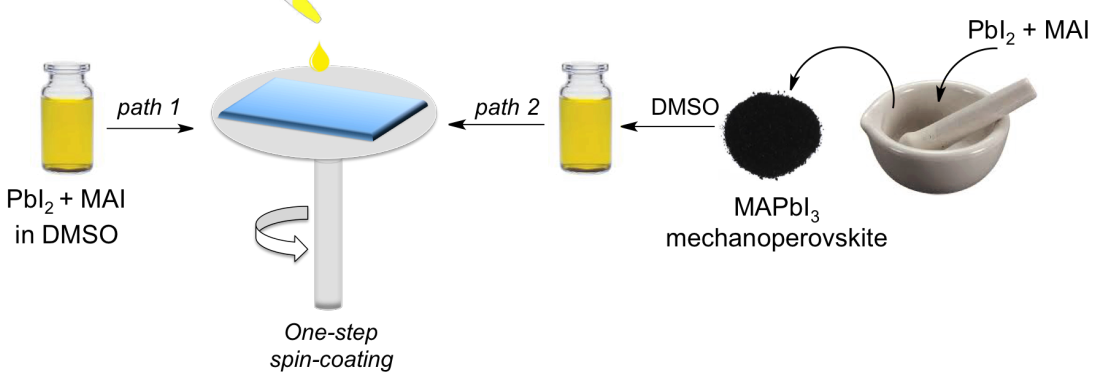

